\title{
OS SABERES DISCENTES DE CIÊNCIAS NATURAIS PARA UMA EDUCAÇÃO AMBIENTAL HOLISTICA NA AMAZÔNIA AMAPAENSE
}

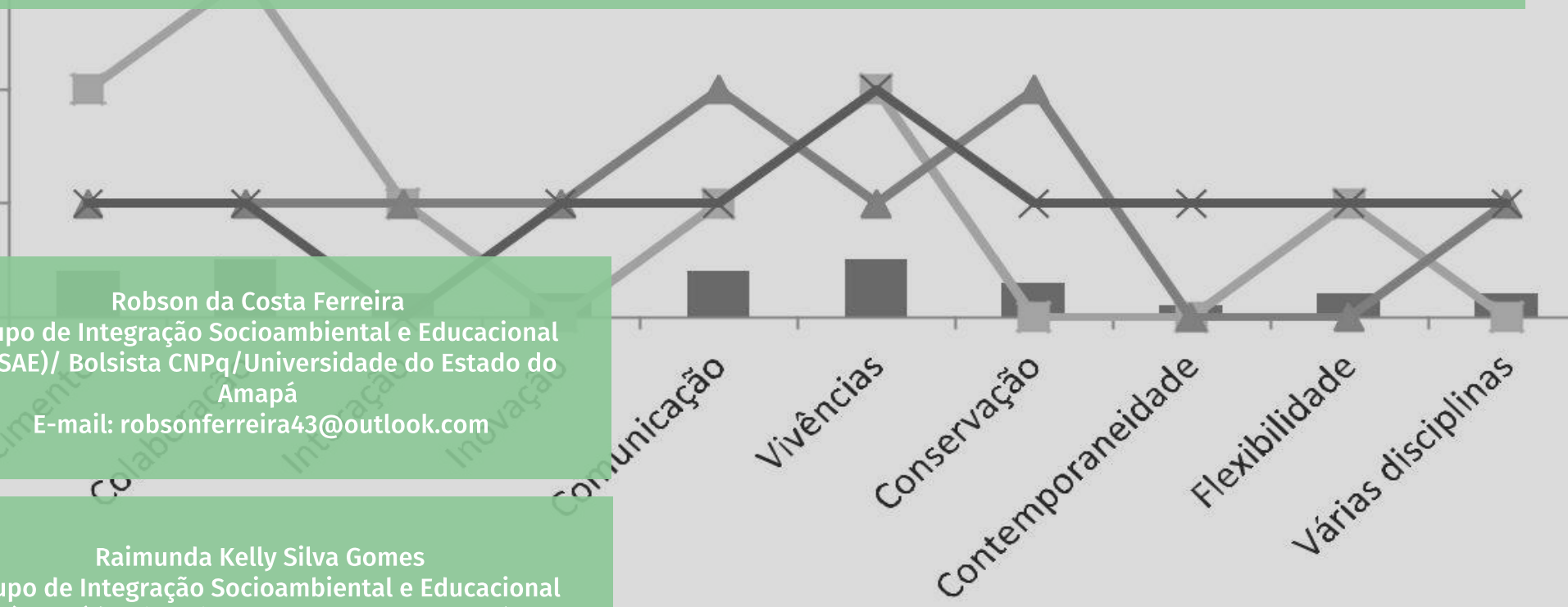

Grupo de Integração Socioambiental e Educacional

(GISAE)/ Universidade do Estado do Amapá

E-mail:rkellysgomes@yahoo.com.br

Palavras-chave que caracterizam Interdisciplinaridade, na percepção dos (as) acadêmicos (as) de Ciências Naturais da UEAP.

\section{RESUMO}

Este trabalho teve como objetivo analisar os saberes e percepções socioambientais dos discentes em anos finais do curso de Licenciatura em Ciências Naturais da Universidade do Estado do Amapá (UEAP). O procedimento metodológico foi desenvolvido em três etapas: 1) levantamento documental dos projetos e planos existentes voltados a Educação Ambiental (EA), no que se refere ao curso de ciências naturais. 2) Entrevistas semiestruturadas com os discentes do curso de Licenciatura em Ciências Naturais. 3) análise qualiquantitativa dos dados coletados. Os resultados apontam que $40 \%$ dos acadêmicos (as) são de famílias de baixa renda e encontram dificuldades para se manter na universidade. De acordo com os acadêmicos pesquisados o curso tem uma boa interação teoria-prática, apesar de não ter possibilitado uma real integração entre o ensino, a pesquisa e a extensão. Por outro lado, os resultados apontam que a EA atua como eixo comum, e que a interdisciplinaridade ainda é um gargalo na formação inicial, pois não conseguem vislumbrá-la em suas práticas pedagógicas. Da mesma forma que não compreendem a complexidade da transversalidade e como ela deve ser inserida na educação formal. Portanto, concluímos que o curso de Ciências Naturais da UEAP ainda não se concretizou como um curso interdisciplinar, mas tem essa possibilidade, sendo a EA um possível caminho de início para a reformulação desse processo de formação.

Palavras-chave: Formação de educadores; Interdisciplinaridade; Socioambiental.

\section{ABSTRACT}

The objective of this work was to analyze the socioenvironmental knowledge and perceptions of students in the final years of the Natural Sciences Degree course at the University of Amapá (UEAP). The methodological procedure was developed in three stages: 1) documentary survey of existing projects and plans focused on Environmental Education (EA), as it relates to the course of natural sciences. 2) Semistructured interviews with the students of the Natural Sciences Degree course. 3) qualitative and quantitative analysis of the data collected. The results indicate that $40 \%$ of the students are from low-income families and find it difficult to remain in university. According to the researched academics, the course has a good theory-practice interaction, although it did not allow a real integration between teaching, research and extension. On the other hand, the results indicate that the EA acts as a common axis, and that interdisciplinarity is still a bottleneck in initial training, since they can not see it in their pedagogical practices. In the same way they do not understand the complexity of transversality and how it should be inserted in formal education. Therefore, we conclude that UEAP's Natural Sciences course has not yet materialized as an interdisciplinary course, but it has this possibility, and EA is a possible starting point for the reformulation of this training process.

Keywords: Training of educators; Interdisciplinarity; Socio-environmental. 


\section{INTRODUÇÃO}

A Educação Ambiental (EA) visa promover uma crítica ao atual modo de apropriação do conhecimento para exploração do ambiente e o debate acerca das limitações do processo civilizatório da vida moderna e suas implicações repercutem diretamente na capacitação da população, atribuindo-lhes responsabilidades diante da crise ambiental existente.

Segundo Carvalho (2012), a EA é considerada inicialmente como uma preocupação dos movimentos ecológicos com a prática de conscientização, que seja capaz de chamar a atenção para a má distribuição do acesso aos recursos naturais, assim como ao seu esgotamento, e envolver os cidadãos em ações sociais ambientalmente apropriadas. Ainda, enfatiza que a educação ambiental deve ser acima de tudo um ato político voltado para a transformação social, capaz de transformar valores e atitudes, construindo novos hábitos e conhecimentos, defendendo uma nova ética, que sensibiliza e conscientiza na formação da relação integrada do ser humano, da sociedade e da natureza, aspirando ao equilíbrio local e global, como forma de melhorar a qualidade de todos os níveis de vida (CARVALHO, 2012).

A incorporação da dimensão ambiental no âmbito da formação constitui-se, assim, em um dos principais desafios a serem enfrentados pelos educadores e pelas instituições de ensino. Entretanto, observa-se que não há ainda a devida clareza acerca dos caminhos mais adequados para que a EA seja integrada na proposta formativa da educação formal (BATISTA; RAMOS, 2011).

Para que a EA se concretize, é necessário capacitar e preparar esses futuros educadores, incorporando a dimensão ambiental em sua formação, para que se torne um educador ambiental, pois, devido à complexidade e abrangência inerentes à temática ambiental, é necessário preparar educadores comprometidos com as questões ambientais e para tanto é imperativo que os cursos de licenciatura ofereçam condições adequadas para formar este tipo de profissional (CAMPOS e CAVALARI, 2017).

A compreensão de que uma formação para a EA ultrapassa a conquista de um diploma acadêmico, necessitando, também, de atualização constante, exercício de práticas pedagógicas inovadoras, conhecimento e abertura para o fazer interdisciplinar, além da perspectiva de que as relações sociedadenatureza são complexas e não devem ser reduzidas a projetos pontuais e sem continuidade, faz emergir uma série de questionamentos sobre o que esta representa e como é pensada (DUARTE et al., 2014).

De acordo com Branco et al. (2018), neste percurso, entre aprendizagens e descobertas, foi se fortalecendo a ideia de que discorrer, estudar e vivenciar práticas acerca da EA é vital e urgente e, na educação formal, não se restringe a determinadas áreas ou disciplinas, mas alude a todas, permeando todo o currículo numa forma interdisciplinar e transversal.

Desse modo, pensando que a EA possui esse potencial de modificar as ações das pessoas em prol de um mundo sustentável, acredita-se ser importante perceber como o sujeito articula seus saberes no ato de educar. Portanto, este projeto teve por objetivo analisar os saberes e percepções socioambientais dos discentes em anos finais do curso de licenciatura em Ciências Naturais da Universidade do Estado do Amapá.

\section{MATERIAIS E MÉTODOS}

\section{Área de estudo}

A Universidade do Estado do Amapá (UEAP) é uma instituição de ensino superior pública, fundada em 31 de maio de 2006. É regida pelos instrumentos normativos: Estatuto; Plano de Desenvolvimento Institucional (PDI); Regimento 
Geral; Projetos Pedagógicos de Cursos. E tem por objetivos: Promover 0 ensino superior, desenvolvendo o conhecimento universal, com especial atenção para o estado do Amapá e para a Amazônia; Realizar pesquisa e estimular atividades criadoras, valorizando o indivíduo em seu processo evolutivo, incentivando o conhecimento científico relacionado ao homem e ao meio ambiente; Participar e colaborar com as políticas de desenvolvimento do Estado do Amapá.

O curso de Licenciatura Plena em Ciências Naturais, baseia-se nos conhecimentos fundamentais das ciências fisicas, químicas e biológicas, voltado para a prática docente em Ensino de Ciências para o Ensino Fundamental II.

\section{Procedimento metodológico}

Esta pesquisa foi desenvolvida em três etapas: 1) levantamento documental dos projetos e planos voltados a educação ambiental, no que se refere ao curso de ciências naturais. 2) entrevistas semiestruturadas com os discentes do referente curso. 3) e por fim, a analise quali-quantitativa dos dados coletados.

Destacamos que iniciamos a referente pesquisa com a realização das entrevistas semiestruturadas, segundo Minayo (2010), com os discentes em anos finais para conclusão do curso de licenciatura em ciências naturais, sendo que através desses dados foi traçado o perfil socioeducativo dos entrevistados. Neste sentido, Chizzotti (2006), considera que estas entrevistas são instrumentos de pesquisa que incorporam indicadores essenciais e suficientes, mantendo a flexibilidade no decorrer das conversas, o que possibilita reunir e organizar um conjunto comprobatório de informações que

\section{RESULTADOS E DISCUSSÕES}

\section{Perfil socioeconômico dos acadêmicos}

undamente o objeto da pesquisa. Após as entrevistas, estruturou-se a base de dados através do pacote estatístico SPSS (Statistical Package Forthe Social Sciences) versão 21.0.

Os (as) acadêmicos (as) do 5o semestre do curso de licenciatura em Ciências Naturais, são $50 \%$ do sexo masculino e $50 \%$ do feminino, em sua maioria solteiros (70\%), na faixa etária de 21 a 30 anos ( $80 \%)$, os quais em geral são naturais de Macapá (70\%) (figura 01). 0 que mostra que o curso é acessivel a todos os públicos e a todas as faixas socioeconômicas da sociedade amapense. No entanto, o curso possui altos indices de evasão, isso fica evidente quando analisamos a quantidades de discentes na turma pesquisada, apenas 10, mas que é perceptivel que esse fato não é isolado, mas comum ao curso e a universidade com um todo.
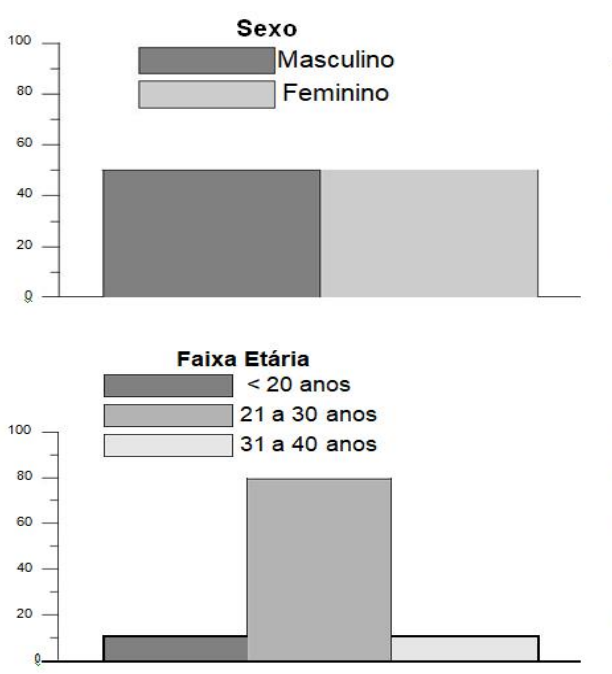

Figura 01: Perfil dos acadêmicos de Ciências Naturais.
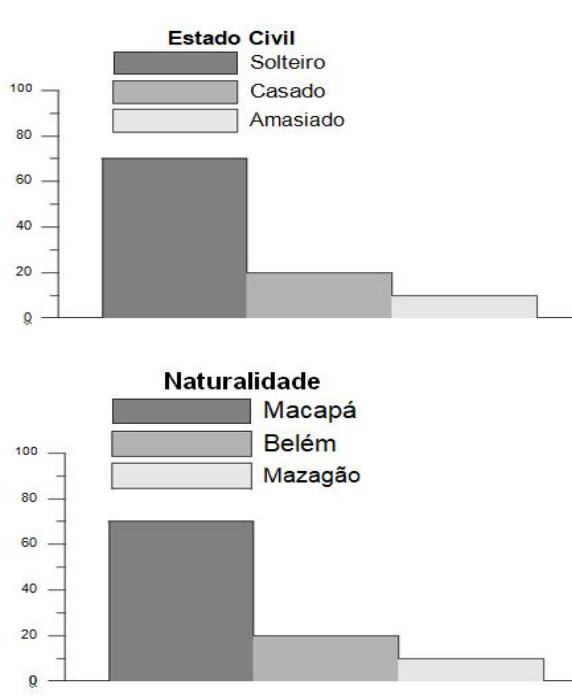

Nas duas últimas décadas, a educação superior brasileira foi marcada por forte expansão sob todos os aspectos, cresceu o número de instituições, de cursos, de vagas, de 
ingressantes, de matrículas e de concluintes, estudantil, $80 \%$ nunca participou dessas proporcionando mudanças no perfil atividades, mas no que se refere ao interesse em socioeconômico dos estudantes de graduação, participar, 50\% afirmou ter interesse em integrar que ficam ainda mais evidentes quando se grupos de estudos (figura 03).

observa a renda familiar dos estudantes (RISTOFF, 2014).

A maioria dos acadêmicos, não possuem nenhum vínculo empregatício (90\%), e um numero significativo possuem renda familiar inferior a um salário mínimo (40\%), fato que mostra a importância dos auxílios estudantis e das
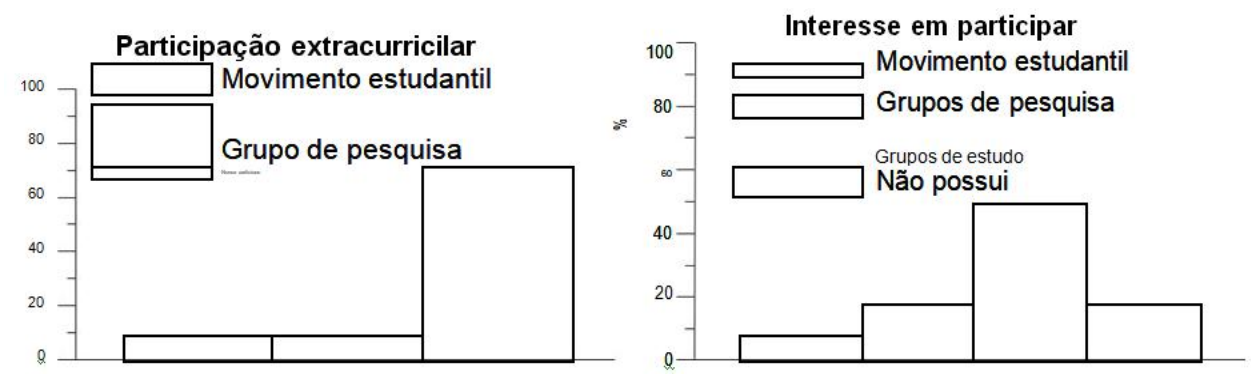

Figura 03: Participação e interesse em atividades extracurriculares. bolsa universitárias para a permanência desses (as) acadêmicos (as) na Universidade (figura 02).

Segundo Barros et al. (2011), os pilares construtores de uma boa universidade são suas poderosas fontes de conhecimento (o ensino, a
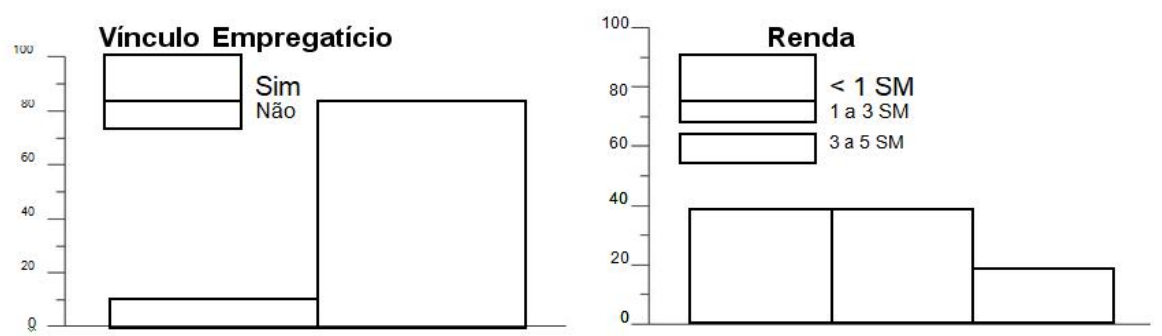
pesquisa e a extensão), estes componentes são facilmente reunidos em formas acadêmicas claras e objetivas de construção e excelência, através dos grupos de pesquisa e de estudo, e estes, em grande parte das vezes, conseguem fazer com que haja uma forte interação entre aqueles três universos que, por vezes, parecem distintos. Logo, participar de um grupo de pesquisa é de grande importância para visualização da aplicação prática dos conhecimentos Figura 02: Vínculo empregatício, renda e auxílios dos acadêmicos. teóricos, além disso, o envolvimento neste

Mesmo que a maior parte sejam tipo de atividade influência fortemente o futuro desempregados e de renda baixa, uma parcela profissional dos (as) acadêmicos (as), seja para recebe assistência estudantil, como auxílio praticar a profissão escolhida com rigor financeiro, que contribui para sua trajetória científico, seja para se tornar um pesquisador acadêmica, pois the fornecer subsídios para que possa se adequar ao objetivo a que se propõe, que é a permanência e conclusão de curso com qualidade.

Quanto a participação dos (as) acadêmicos (as) em atividades extracurriculares, verificamos que somente $20 \%$ estão vinculados ao grupo de pesquisa, grupos de estudos e/ou movimento (BARROS et al., 2011).

Portanto, o perfil dos (as) acadêmicos (as) de Ciências Naturais é comum aos outros cursos da universidade e até mesmo ao Amapá de maneira geral, sendo a maioria proveniente da rede publica de ensino, com muitas dificuldades de permanência na universidade. 


\section{Formação}

Quanto ao nivel de satisfação com o curso, verificamos que $60 \%$ estão dos entrevistados estão satisfeitos (figura 04), embora apontem que um dos principais problemas do curso no momento, seja a falta de infraestrutura, em especial dos laboratórios. Esse bom índice satisfação está diretamente relacionado com a relação dos (as) acadêmicos (as) com os (as) professores (as), além das aulas de laboratório e de campo, que fazem com que os mesmos sentem-se motivados a participar dessas atividades, que na maioria das vezes são interessantes e, até mesmo, mais prazerosas que as aulas tradicionais, além de facilitarem o aprendizado.

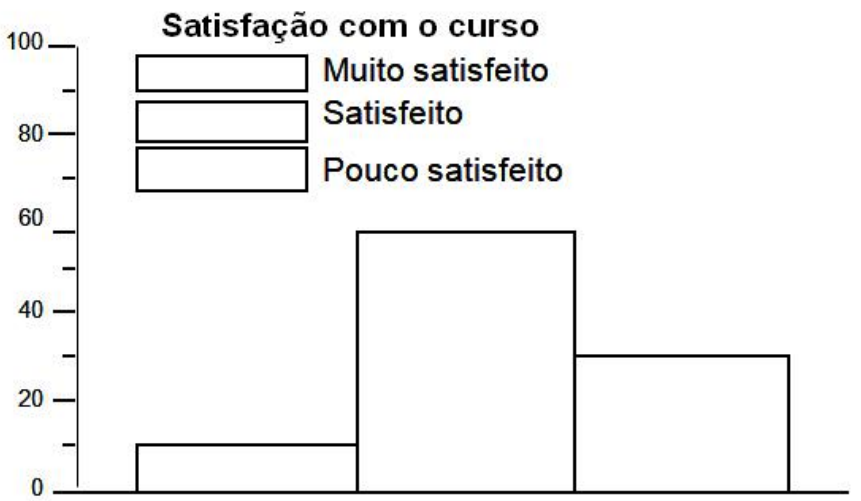

Figura 04: Nivel de satisfação com o curso de Ciências Naturais.

Segundo pontuam Souza e Reinert (2010, p. 171), "as categorias estrutura curricular e corpo docente emergiram como fatores que mais influenciam tanto a satisfação quanto a insatisfação dos estudantes com o curso". Esta que envolve o atendimento das expectativas dos acadêmicos. É importante ressaltar que essa satisfação com o curso, é um dos pontos a se estudar como um influenciador (entre outros) nos níveis de evasão universitária.

Os (as) acadêmicos (as) do curso de ciências naturais foram questionados sobre o que o curso de licenciatura mais tem possibilitado no decorrer da formação, a maioria mencionou que o curso tem uma boa interação teoria-prática.
Também tiveram citações como: referencial teórico adequado; adequação das demandas profissionais; propostas didáticas pedagógicas inovadoras; adequação as propostas atuais para a educação básico. Mas a maior frequência foi o da interação teoria-prática, justificadas, por eles, pelas aulas de campo e de laboratório, por projetos de extensão do curso e por algumas disciplinas específicas, como observamos na seguinte fala:

Possibilita principalmente nas 4 disciplinas de estágio e docência e 4 práticas pedagógicas, umas das disciplinas que predominam no que diz respeito à aplicação da teoria vista no decorrer do curso, mas não menos importante, as práticas de laboratório, que tem grande importância no conhecimento científico, e, as viagens de campo que nos possibilitam uma visão mais concreta do que se estuda na teoria (A 06).

Segundo Lima e Gonçalves (2009), a teoria e a prática caminham juntas, pois é a teoria que esclarece e enriquece a prática e esta dá novas significações à teoria. A prática como fundamentação da teoria deve transformar o social. Por outro lado, a teoria não é apenas uma justificativa para uma prática. A teoria pode adiantar-se à própria prática, influenciando seu desenvolvimento para uma prática transformadora (VAZQUEZ, 1990, apud LIMA E GONÇALVES, 2009).

Além da boa interação entre a teoria e a prática, que os alunos citam como um dos mais importantes aspectos do curso, também elencaram outros, como o referencial teórico adequado, para qual dão todo o crédito para os professores, que além de atualizados, buscam constantemente propostas didáticas inovadoras. Bem como essas práticas influenciam e contribuem para a introdução do ensino interdisciplinar no curso.

No decorrer das entrevistas os (as) acadêmicos (as) de ciências naturais foram 
questionados sobre as disciplinas, se estavam possibilitando uma visão interdisciplinar e, que citassem um exemplo. Diante disso, todos afirmaram que sim, e para explicarem, fizeram uma relação entre duas ou mais disciplinas, ou sobre os conteúdos ministrados nas disciplinas, como podemos perceber nas seguintes explicações:

Sim, podemos perceber que sempre os professores tentam linkar os conteúdos ministrados nas aulas com a realidade onde vivemos. Ex: Filmes onde analisamos aspectos biológicos (A 01).

Sim, pois é possivel perceber que determinadas disciplinas completam outra. Ex: Aula de campo na APA da Fazendinha (Ecologia

Etnoconservação) (A 08).

Sim, cruzando conhecimentos prévios, conceitos científicos. Ex: Na disciplina de química utilizamos conceitos de física para entender as leis de atração e repulsão (A 03).

Diante disso, é explicito que os (das) acadêmicos (as) ainda não compreendem a interdisciplinaridade, pois, dizem ser apenas a relação entre disciplinas. Isso, leva-nos a pensar a forma como esse ensino interdisciplinar está sendo apresentado nesse processo de formação, uma vez que, o ensino interdisciplinar pretende formar alunos com uma visão global de mundo, com capacidade para articular e contextualizar, situar-se num contexto e, se possivel, globalizar, reunir os conhecimentos adquiridos de forma rápida e prática (MORIN, 2002). Assim como a Interdisciplinaridade, é a "necessidade básica para conhecer e modificar o mundo é possivel de concretizar-se no ensino através da eliminação das barreiras entre as disciplinas e entre as pessoas" (FAZENDA, 2002, p. 95).

Também foram questionados se o curso tem possibilitado a integração entre o ensino, a pesquisa e a extensão, e obtivemos como resultado que o curso integra esses eixos, porém quando vão explicar suas afirmações aparentam não ter um bom entendimento do tema, e acabam citando como incentivadores grupos e programas que não são fomentados pelo curso e nem pela universidade, como o PIBIC e o PIBID, que foram bastantes citados, mas que são programas fomentados pelo CNPq e CAPES respectivamente, mas que são de grande importância para o processo de formação dos acadêmicos. Para explicitar isso, segue algumas das respostas dos acadêmicos:

Sim. Além das aulas práticas e teóricas, o colegiado de Ciências Naturais apoia e incentiva os acadêmicos a participarem de programas como PIBID, PIBIC, projetos de extensão e etc. (A 05).

Sim, através das bolsas (iniciação científica e docente) e grupos de pesquisas (A 10).

Sim, através dos grupos de iniciação científica (A 02).

Sim, ensino através dos minicursos e palestras propostas. Pesquisa, através dos programas e grupos de pesquisa, como o PIBID. Extensão através de estágios e trabalhos aplicados por professores (A 06).

Diante das falas dos (as) acadêmicos (as) percebeu-se que o curso tem um excelente ensino e bom incentivo a pesquisa, tanto pela iniciação científica como pelas disciplinas, porém, falta incentivo a extensão. De acordo com Moita e Andrade (2009), pesquisa, ensino e extensão articulam-se, na formação acadêmica, de modo a promover uma consciência profissional eticamente fundamentada e empiricamente atualizada. Bem como, essa articulação deve ser uma relação entre universidade e sociedade, numa partilha de saberes entre pesquisadores e utilizadores (SANTOS, 2004).

Assim, os (as) acadêmicos (as) de ciências naturais aparentaram ter pouca ou nenhuma familiaridade com a maioria dos temas abordados. E podemos comprovar isso através das falas supracitadas, quando buscam outras 
formas e/ou exemplos para tentar explicar o que lhes foi questionado. Porém, dentro das falas verificou-se que o curso de Ciências Naturais está bem articulado, em especial em seu quadro de professores, mas que precisa se reformular interdisciplinar.

\section{Percepções dos acadêmicos de ciências naturais sobre Interdisciplinaridade, transversalidade, sustentabilidade e EA.}

$\mathrm{Na}$ tentativa de compreendermos a percepção sobre Interdisciplinaridade dos acadêmicos do 5o semestre do curso de Licenciatura em Ciências Naturais da UEAP, solicitamos que caracterizassem em três palavras (substantivos) o que entendem por Interdisciplinaridade, como opção 1, 2 e 3 de acordo com a ordem de importância, como explicitamos nos resultados apresentados na Figura 05. para se tornar um curso verdadeiramente

vivências como a união dos saberes empíricos, seguidas pela palavra conhecimento que foi apresentada como formas de saberes acadêmicos e científicos ( $40 \%)$, também com $40 \%$ a palavra comunicação, sendo que ao referila se reportavam a interação entres saberes a às disciplinas.

Verificamos a presença da palavra conservação, a qual é utilizada para expressar uma interação social pautada na sustentabilidade, afim de melhorar a relação homem x natureza. Pois, de acordo com Ravena (2010), a ideia conservação é uma opção cultural demonstrada por determinados grupos, visando a interação com o meio ambiente em bases de preservação, que incluem alternativas como controle populacional, estratégias de exploração de recursos que mantêm as bases de organização social, contribuindo diretamente para o desenvolvimento sustentável.

O grande desafio do nosso tempo construir e desenvolver a sustentabilidade, para tanto a formação humana deve ser posta como prioridade no processo educacional instigando o convívio social do indivíduo com a natureza (CAPRA, 2006).

Dessa forma, Loureiro (2015) ressalta que a sustentabilidade para ser efetivada necessita da interrelação existente nas manifestações culturais, evidenciada pela autonomia de decisão do povo, do uso das características de um determinado ecossistema, tendo por base a dinâmica territorial existente.

Figura 05: Palavras-chave que caracterizam Interdisciplinaridade, na percepção dos (as) acadêmicos (as) de Ciências Naturais da UEAP.

De acordo com a figura 05 verificamos que $50 \%$ das palavras-chaves foram relacionadas à colaboração, independente das sequência de opção dos acadêmicos sobre o conceito de Interdisciplinaridade, explicaram no sentido de colaboração entre as disciplinas, $50 \%$ a palavra
Os acadêmicos de Ciências Naturais usaram a expressão "Várias disciplinas" para referenciar a interdisciplinaridade como com a junção de disciplinas diferentes, como uma relação de troca de saberes e experiências, que também é expressada com sinônimo de interação, mas que 
pode ter um viés ampliado, indo além da mera relação entre disciplinas, mas que pode ser entendida com a unificação do conhecimento.

Além disso, verificamos outras palavras, como contemporaneidade, que foi referida ao que está sempre inovando e evoluindo, seguido por inovação, sendo justificada pela busca de novas ferramentas que facilitem e desenvolvam o ensino, por fim a palavra flexibilidade, sendo apresentada como uma necessidade de áreas de conhecimento ou das próprias disciplinas, como requisito para que a interdisciplinaridade possa surgir e caminhar por esses meios.

Diante disso, Carvalho (2012) afirma que a EA possibilita alternativas renovadoras no sistema de ensino, de organização e dos conteúdos escolares, pautando-se numa revisão da instituição e do cotidiano escolar, mediante os atributos da transversalidade e da interdisciplinaridade, articulando os processos pedagógicos com os conhecimentos ambientais, através da interdisciplinaridade dos sujeitos e de sua relação com a natureza.

Um dos maiores desafios da EA na atualidade é garantir o desenvolvimento de um currículo pautado numa perspectiva interdisciplinar, transversal e problematizadora da realidade socioambiental que "atravessa" o currículo escolar no processo educativo (TORRES et al., 2014).

Portanto, compreender a relação entre a forma como os (as) acadêmicos (as) constroem seus saberes e os integram a sua prática discente, pode servir de fundamento para entender e repensar a inserção da EA no ensino formal de forma transversal. Por esta razão buscamos compreender o entendimento dos discentes de Ciências Naturais sobre a transversalidade, os quais fizeram os seguintes relatos:

Várias opções de ver o ensino e ajudando-o a melhorar com outras alternativas (A 04).
Teoria, prática e aprendizado, porque sem a teoria não teria uma noção de como se comportar na prática e aprender com ela (A 09).

Discussão que se procura conhecer e apresentar temas novos. Independência que não se preocupa com especificidades ou barreiras, essencial para melhor esclarecimento de temas pouco discutidos (A 06).

Não sei no momento o que significa transversalidade (A 08).

Esse conceito ainda me é desconhecido (A 07).

Não domino (A 02).

Não sei (A 01).

Verificamos a presença das expressões "opções de ver o ensino" e "ajudando-o a melhorar" com a justificativa de que a transversalidade apresenta-se como novas propostas de analisar o ensino, buscando seu desenvolvimento de a forma a melhorar em todos os seus níveis. Também identificamos as citações "não se preocupa com especificidades ou barreiras" e "esclarecimento de temas pouco discutidos" que mostram uma visão mais aproximada da transversalidade, mesmo que essa aproximação do real sentido do transdisciplinar seja vaga, pois confunde-se bastante com a interdisciplinaridade.

Por outro lado, diante dos relatos, observamos as expressões "não sei no momento", "ainda me é desconhecido", "não domino" e "não sei" nas quais é implícito que os acadêmicos possuem pouco ou nenhum conhecimento sobre a transversalidade. Os acadêmicos atribuem a esta falta de informação específica, principalmente, aos déficits do inicio da formação, pois a academia até o momento não oportunizou a discussão dessa temática.

Destacamos que a transversalidade no currículo escolar é abordada por Matias (2008) como um rizoma, ao relacioná-la com seus sistemas descentralizados, sem hierarquias e 
reprodução de saberes, pois proporciona mobilidade em todos os sentidos e direções, para além das propostas interdisciplinares. Mas como a análise dos saberes transversais dos acadêmicos percebemos que a idéia de transversalidade contida neles é outra, sem elaboração, que condiz apenas com os limites disciplinares.

Cabe destacar que o novo paradigma do ensino superior discutido por Lucchesi e Malanga (2011), preconiza que o ensino superior instaure a pesquisa como fundamento do ensino e que isso seja feito na ultrapassagem das fronteiras disciplinares, uma vez que o mundo caminha para uma integração cada vez maior do conhecimento, isto só será possível com a superação dos limites das disciplinas, que se dá pela interdisciplinaridade e, posteriormente, com essa unificação do currículo, pela transdisciplinaridade.

Assim, este vasto e amplo campo de estudo deve permear todo o currículo da educação. Porém, como o currículo ainda é fragmentado em disciplinas, buscamos entender como as práticas pedagógicas tem contribuído para compreender o conhecimento transversal e interdisciplinar dentro do curso de Ciências Naturais, dos quais tivemos os seguintes relatos:

Sim, pois através disso nós podemos enxergar o conhecimento como "um só corpo", e não recortes da ciência cartesiana (A 05).

Sim, pois relaciona os conteúdos das disciplinas (A 01).

Sim, graças a prática tenho visto o quanto posso trabalhar a disciplina de ciências em qualquer outra disciplina de acordo com o método escolhido para determinada situação (A 04).

Sim, conhecimento sendo absorvido de várias maneiras, tanto de regência como de observação (A 06).

Sim, desperta no aluno um olhar pedagógico, didático (A 02).

Sim, pois trás consigo o conhecimento teórico de vários autores importantes para a educação, mostrando de que forma deve ser tratado um determinado assunto (A 08).

De acordo com os relatos podemos averiguar que a inserção das práticas pedagógicas no curso de Ciências Naturais tem sido efetivada, sendo perceptível por meio das expressões "conhecimento como 'um só corpo'", "relaciona os conteúdos" e "disciplina de ciências em qualquer outra disciplina". Embora os acadêmicos não compreendam o real sentido da interdisciplinaridade e da transversalidade, como já foi destacado anteriormente nessa pesquisa.

Assim, entendemos que as práticas pedagógicas devem ser a porta de entrada para o ensino transversal e interdisciplinar, considerando que esse conjunto de práticas educativas, estreitaria as relações com a educação e suas tradições pedagógicas, com orientações específicas dentro da EA (LIMA, 2015).

A EA na formação de educadores assume o desafio de provocar mudanças na vida cotidiana dos indivíduos, dando ressignificação a relação do homem com a sua natureza e, consequentemente para um futuro sustentável (LEFF, 2010).

Neste sentido, Guimarães (2011) aborda que a EA volta-se para uma ação reflexiva (teoria e prática-práxis) de intervenção em uma realidade complexa, pois seus conteúdos não estão trilhados nos livros, mas na realidade socioambiental vivenciada, fato que a torna uma educação política voltada para a transformação da sociedade em busca da sustentabilidade.

Portanto, compreender a forma como os acadêmicos constroem seus saberes pode servir de fundamento para entender e repensar a inserção da EA no ensino formal. Por esta razão buscamos compreender o entendimento dos acadêmicos de Ciências Naturais sobre a 
sustentabilidade, os quais fizeram os seguintes relatos:

Compreendo por controlar o desperdício de recursos hídricos (A 09).

Ações humanas que devem ser tomadas de modo que não degrade o meio ambiente (A 01).

É usar os recursos sem acabar com eles, de forma a repor o que foi tirado (A 08).

É a utilização adequada de recursos visando o fim do desperdício e seu esgotamento (A 03).

Tudo que pode ser utilizado ou reutilizado para a melhoria ambiental (A 06).

Maneira ecológica de preservação (A 10).

É a utilização racional dos recursos naturais, suprindo as necessidades do hoje sem comprometer as gerações futuras (A 05).

Cuidar, preservar, economizar, dinamizar, reinventar (A 04).

De acordo com os relatos, a maioria dos acadêmicos sentiu dificuldade de expressar o que entendem por sustentabilidade, pois verificamos expressões como "controlar $\mathbf{0}$ desperdicio", "usar os recursos sem acabar", "utilização racional", "economizar", que focam apenas em possiveis ações que possam minimizar alguns problemas ambientais. Da mesma forma que a "melhoria ambiental" e a "preservação" são apresentadas como possíveis resultados, caso as ações citadas anteriormente sejam implementadas e vivenciadas. Com isso, evidenciam apenas medidas a serem traçadas, que demonstram essa vaga compreensão dos acadêmicos sobre 0 real significado de sustentabilidade, da complexidade ambiental e da sua efetivação nas práticas humanas.

Loureiro (2015) ressalta que a sustentabilidade para ser efetivada necessita da inter-relação existente nas manifestações culturais, evidenciada pela autonomia de decisão do povo, do uso das características de um determinado ecossistema, tendo por base a dinâmica territorial existente. Para isso, o professor possui como papel principal dentro desse processo, porém deve passar por um processo de formação para ir além e se tornar um educador ambiental.

De acordo com Duarte et al. (2014), além de expor os desafios e complexidades da temática ambiental, é preciso que o educador tenha uma postura diferenciada e integradora do homem e natureza, mostrando que a mobilização social frente às questões ambientais só pode se dar com uma visão de mundo que englobe uma cidadania e ética condizentes com a perspectiva ambiental.

Neste sentido, entendemos que os pesquisados passem por um processo de formação identitária, que integrem os conhecimentos formais e os saberes do cotidiano dos indivíduos, para que se constituam potenciais educadores ambientais, 0 que possibilitará o empoderamento e a emancipação destes profissionais (CAMPOS e CAVALARI, 2017).

Cientes da necessidade de se formar profissionais conscientes e preocupados com a problemática ambiental e sua relação com as sociedades, buscamos entender a compreensão dos acadêmicos de licenciatura em Ciências Naturais sobre a EA, e obtivemos os seguintes relatos:

Entendo por estudar o meio ambiente (A 09).

A formação de indivíduos para que tenham uma boa relação com o meio onde vive (A 01).

Seria aprender o que se pode ou não fazer com o ambiente, o que seria melhor para ambos (A 08).

Uma forma de conscientização sobre o uso e manejo da natureza e ambiente que estamos inseridos (A 07).

Preservação do meio ambiente natural, valorização de práticas educativas, 
consciência do futuro (A 02).

Preservação de fauna e flora e a manutenção do meio em que vivemos (A 03).

Integração do meio ambiente com metodologias para aplicar a prática (A 06).

A Educação Ambiental possibilita a formação de indivíduos ecologicamente corretos que são capazes de administrar os recursos naturais de forma correta ( $A$ 05).

Uma educação voltada para a reeducação ambiental do ser humano para o mesmo possa viver em consonância com o meio ambiente (A 04).

De acordo com os relatos expostos, verificamos as expressões "conscientização", "preservação" e "consciência do futuro", mostrando que os acadêmicos entendem a EA apenas com uma visão conservacionista, pois retratam a EA como solução para problemas ambientais por meio da preservação e conservação. As frases "estudar o meio ambiente" $e$ "relação com o meio", demonstram o olhar naturalista dos pesquisados.

Diante desse problema, Guimarães e Alves (2012), sinalizam a necessidade de transformação de um padrão societário, levando o foco para a EA e para uma formação de educadores que seja crítica e que contemple, nessa perspectiva, uma EA emancipatória, já que a atuação desses sujeitos é fundamental na dinamização dos processos de transformações socioambientais.

Por outro lado, verificamos as expressões "formação de indivíduos ecologicamente corretos", "reeducação ambiental" $e$ "viver em consonância com o meio ambiente", que apontam, mesmo de forma tímida, para a corrente epistemológica da EA holística, que as realidades socioambientais são percebidas por múltiplas dimensões. Porém, no decorrer da pesquisa verificamos que os entrevistados não conseguem fazer essas distinção das diferentes correntes dentro da EA, provando que entendem muito pouco do seu real sentindo dentro do ensino. Isso pode se explicar pelo fato de o curso de Ciências Naturais oferecer uma disciplina de EA. Sendo que a EA deveria ser integrada como um eixo transversal dentro do currículo do curso.

Guimarães e Cardoso (2014) afirmam que esta visão de EA acaba contribuindo para que esta seja vista como uma atividades pontual/esporádica, estanque, sem maiores reflexões com o todo, não abarcando a complexidade socioambiental da realidade, sendo que a EA holística é entendida na compreensão das contradições do sistema, que busca entender as múltiplas determinações políticas, econômicas, culturais do tempo histórico e a materialidade das relações do ser humano em sociedade com a natureza, e com outro ser humano.

Portanto, é preciso que a EA seja compreendida na complexidade da questão ambiental e suas implicações na vida cotidiana dos indivíduos, o que nos remete a compreender a relação entre a forma como constroem seus saberes, e pretendem integrá-los a sua prática, como elementos fundamentais para entender $\mathrm{e}$ repensar a inserção da EA no ensino formal.

\section{CONSIDERAÇÕES FINAIS}

Com os resultados deste estudo foi possivel identificar através do perfil socioeconômico dos acadêmicos de ciências naturais que a maioria enfrenta dificuldades para se manter na universidade, o que torna notória a importância das bolsas de auxílio e incentivo universitário para a continuação dos cursos de graduação. Complementar a isso, tem as participações em atividades extracurriculares, que envolvem os participantes ajudando-os em seu processo de formação pessoal e curricular, principalmente os que estão relacionados à pesquisa e à extensão. 
Quanto à satisfação com o curso podemos observar que a maioria dos pesquisados estão satisfeitos, principalmente no que se refere à relação professor $x$ aluno. Isso se dá justamente por eles considerarem como ponto forte do curso a boa interação entre a teoria e a prática, pois isso possibilita com que as disciplinas se aproximem cada vez mais umas das outras, facilitando o aprendizado, além de possibilitar um bom acesso ao ensino, a pesquisa e, mesmo que limitado, a extensão.

No que se refere aos saberes dos acadêmicos sobre interdisciplinaridade, observamos que os mesmos sabem de conceitos, mas não entendem o real significado para o processo de formação. Enquanto que a transversalidade ainda é um conceito desconhecido pela maioria dos pesquisados.

Outro ponto a ser destacado nesta pesquisa é a percepção dos acadêmicos sobre sustentabilidade, os quais restringem a preservação e a conservação, da mesma forma que entendem a importância que a EA tem nesse processo, porém, ainda a entendam somente como uma disciplina que terão no último semestre. Portanto, concluímos que o curso de licenciatura em Ciências Naturais da UEAP ainda não se concretizou como um curso interdisciplinar e transversal, mas tem essa possibilidade, sendo a EA um possível caminho de início para a reformulação desse processo de formação.

\section{REFERÊNCIAS}

BARROS, W. M.; ALVES, N.; MENEZES, J.; CARPES, P. B. M.; A importância da participação em Grupos de Pesquisa e a relação entre essa escolha e o futuro do integrante. Anais do Salão

Internacional de Ensino, Pesquisa e Extensão, v. 3, n. 2, 2011. Disponível em:

<http://seer.unipampa.edu.br/index.php/siepe /article/view/3406>. Acesso em: 28 jul. 2018.

BATISTA, M. S. S.; RAMOS, M. C. P. Desafios da
Educação Ambiental no ensino superior : das políticas às práticas no Brasil e em Portugal. 2011. Disponível em:

<http://www.anpae.org.br/simposio2011/cdrom 2011/PDFs/trabalhosCompletos/comunicac oesRelatos/0356.pdf>. Acesso em: 05 mai. 2017.

BRANCO, A. B. G.; ROYER, M. R.; NAGASHIMA, L. A. A formação docente para a educação ambiental: investigando conhecimentos e práticas. Rev. Eletrônica Mestr. Educ. Ambient. Rio Grande, v. 35, n. 1, p. 112-131, jan./abr. 2018.

BRASIL. Parâmetros Curriculares Nacionais Ciências Naturais. Brasília, 1998.

CAMPOS, D. B.; CAVALARI, R. M. F. Educação Ambiental e formação de professores enquanto "sujeitos ecológicos": processos de formação humana, empoderamento e emancipação. Rev. Eletrônica Mestr. Educ. Ambient., v. 34, n.1, p. 92107, 2017.

\section{CAPRA, F. Falando a linguagem da natureza:}

Principios da sustentabilidade. In: STONE, M. K.; BARLOW, Z. (Org.). Alfabetização ecológica: a educação das crianças para um mundo sustentável. São Paulo: CULTRIX, 2006.

CARVALHO, I. C. M. Educação Ambiental: a formação do sujeito ecológico. São Paulo: Cortez, 2012.

CHIZZOTTI, A. Pesquisa em ciências humanas e sociais. $1^{\circ}$. Edição. São Paulo: Cortez: Biblioteca da Educação, 2006. 375 p.

DUARTE, V. S.; KNECHTEL, M. R.; LOOSE, E. B.; MARTÍNEZ, J. G.; GONÇALVES, L. P.; GIACOMITTI, R. B. A Formação do Educador Ambiental em Debate: uma perspectiva interdisciplinar sobre o perfil deste profissional. Pesquisa em Educação Ambiental, vol. 9, n. 2 - págs. 98-113, 2014.

\section{FAZENDA, I. C. A. Integração e}

interdisciplinaridade no ensino brasileiro: efetividade ou ideologia. São Paulo, SP: Loyola, 2002. Disponível em:

<http://www.pucsp.br/gepi/downloads/PDF_LIV 
ROS_INTEGRANTES_GEPI/livro_integrac ao_interdisciplinaridade.pdf>. Acesso em: 20 jan. 2018.

GUIMARÃES, M. A formação de educadores ambientais. Campinas, São Paulo: Papirus, 2011. GUIMARÃES, M.; CARDOSO, C. Dos desertos geográficos a desertificação da vida: A educação ambiental em tempos de crise. Rev. Eletrônica Mestr. Educ. Ambient., v. 31, p. 324-338, 2014. GUIMARÃES, J. M. M. ALVES, J. M. Formação de professores na área de Educação Ambiental: uma análise dos anais da ANPEd (2009-2011). Pesquisa em Educação Ambiental, vol. 7, n. 1-pp.49-67, 2012.

LEFF, E. Discursos sustentáveis. São Paulo: Cortez, 2010.

LIMA, M. S. L.; GONÇALVES, H. H. A práxis docente no desempenho das atividades do professor formador. In: IX CONGRESSO NACIONAL DE EDUCAÇÃO - EDUCERE

\section{ENCONTRO SUL BRASILEIRO DE}

PSICOPEDAGOGIA, 9., 2009, Curitiba. Disponível em:

<http://www.pucpr.edu.br/eventos/educere/ed ucere2009/anais/trabalhos_9.html>. Acesso em: 17 jan. 2018.

\section{LOUREIRO, C. F. B. Educação ambiental e} educação para o desenvolvimento sustentável: polêmicas, aproximações e distanciamentos. In: LOUREIRO, C. F. B.; LAMOSA, R. A. C. (orgs). Educação ambiental no contexto escolar: um balanço crítico da década da educação para o desenvolvimento sustentável. Rio de janeiro: Quartet: CNPQ, 2015.

LUCCHESI, M. A. S.; MALANGA, E. B. PósDisciplinaridade e Pesquisa Ambiental na Universidade Brasileira: a Amazônia. AMBIENTE \& EDUCAÇÃO, vol. 16(2), 2011.

MATIAS, V. A transversalidade e a construção de novas subjetividades no currículo escolar. Currículo sem Fronteiras, n.1, v.8, p.62-75, 2008. MINAYO, M. C. de S. 0 desafio do conhecimento:
Pesquisa Qualitativa em Saúde. (12a edição). São Paulo: Hucitec-Abrasco, 2010.

MOITA, F. M. G. S. C.; ANDRADE, F. C. B. Ensinopesquisa-extensão: um exercício de indissociabilidade na pós-graduação. Revista Brasileira de Educação, v. 14 n. 41, 2009. p. 269393. Disponível em:<http://www.scielo.br/pdf/rbedu/v14n41/v1 4n41a06.pdf>. Acesso em: 17 jan. 2018.

MORIN, E. A cabeça bem-feita. repensar a reforma, reformar o pensamento.7. ed. Rio de Janeiro: Bertrand Brasil, 2002.

RAVENA, N. Ecologia política e estratégias de sustentabilidade: uma reflexão teórica. Novos Cadernos NAEA, v. 13, n. 2, p. 103-120, dez. 2010. Disponivel em: <https://periodicos.ufpa.br/index.php/ncn/arti cle/view/477>. Acesso em: 28 jul. 2018.

RISTOFF, D. 0 novo perfil do campus brasileiro: uma análise do perfil socioeconômico do estudante de graduação. Avaliação, Campinas, SP, v. 19, n. 3, p. 723-747, 2014. Disponivel em: <http://www.scielo.br/pdf/aval/v19n3/10.pdf>. Acesso em: 28 jul. 2018.

SANTOS, B. S. (Org.). Conhecimento prudente para uma vida decente. São Paulo: Cortez, 2004. p. 757-776.

SOUZA, S. A. REINERT, J. N. Avaliação de um curso de ensino superior através da satisfação/ insatisfação discente. Revista da Avaliação da Educação Superior, Sorocaba, vol. 15. n. 1, p. 159176, 2010. Disponivel em:

<http://www.redalyc.org/html/2191/2191148780 09/>. Acesso em: 24 jan. 2018.

TORRES, J. R.; FERRARI, N.; MAESTRELLI, S. R. P. Educação ambiental crítico transformadora no contexto escolar: teoria e prática Freireana. In: LOUREIRO, C. F. B.; TORRES, J. R. (Org.). Educação Ambiental: dialogando com Paulo Freire. São Paulo: Cortez, 2014.

VAZQUEZ, A. S. Filosofia da práxis. 4a. ed. Rio de Janeiro: Paz e Terra, 1990. 